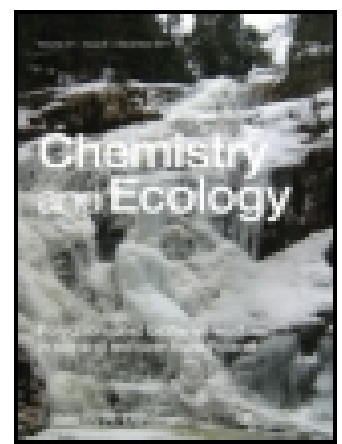

Chemistry and Ecology

\title{
Effects of leonardite on the coastal saline soil improvement
}

Jie Wang , Jun Wu , Jian Lu \& Guodong Yuan

To cite this article: Jie Wang , Jun Wu , Jian Lu \& Guodong Yuan (2020): Effects of leonardite on the coastal saline soil improvement, Chemistry and Ecology, DOI: 10.1080/02757540.2020.1787997

To link to this article: https://doi.org/10.1080/02757540.2020.1787997

曲 Published online: 07 Jul 2020.

Submit your article to this journal

Џ Article views: 3

Q View related articles $\sqsubset$

View Crossmark data $\complement \pi$ 


\title{
Effects of leonardite on the coastal saline soil improvement
}

\author{
Jie Wang ${ }^{a, b}$, Jun Wu ${ }^{c}$, Jian $L^{a, b}$ and Guodong Yuan ${ }^{a, d}$ \\ ${ }^{a}$ CAS Key Laboratory of Coastal Environmental Processes and Ecological Remediation, Yantai Institute of \\ Coastal Zone Research (YIC), Chinese Academy of Sciences (CAS); Shandong Key Laboratory of Coastal \\ Environmental Processes, YICCAS, Yantai Shandong, People's Republic of China; ${ }^{b}$ University of Chinese \\ Academy of Sciences, Beijing, People's Republic of China; 'School of Resources and Environmental \\ Engineering, Ludong University, Yantai, People's Republic of China; ${ }^{\mathrm{d}}$ Zhaoqing University, Zhaoging, People's \\ Republic of China
}

\begin{abstract}
This study investigated the influence of leonardite on coastal saline soil YX1 (very slightly saline), YX2 (slightly saline) and YX3(strongly saline) with $0 / 10 / 30 / 50 \mathrm{~g} / \mathrm{kg}$ addition dosage during the 81-day incubation. Changes of $\mathrm{pH}$, electrical conductivity, soil texture, micromorphology, functional groups and mineral constituents of soil were discussed. Results showed that the application of leonardite enhanced the urea hydrolysis, increased the activities of urease and phosphatase in the coastal saline soil. The urease and phosphatase activity reached the maximum on the 8th incubation day. Leonardite raised $\mathrm{C}$ and $\mathrm{N}$ content in the soil colloid as well as the $\mathrm{C} / \mathrm{N}$ value. However, leonardite had limited effects on the soil texture and mineral components during the incubation period. The application of leonardite would promote the activity of soil micro-organisms and relative enzyme to improve the soil ecosystem. It could benefit the amelioration of coastal saline soil, and provide the theoretical direction for agricultural production.
\end{abstract}

\section{ARTICLE HISTORY}

Received 7 January 2020

Final Version Received 23

June 2020

\section{KEYWORDS}

Coastal saline soil; leonardite; amelioration; incubation; Yellow River Delta

\section{Introduction}

The coastal saline soils have been widely distributed on a global scale. About 1100 million hectares of land in the world have been affected by salinity to varying degrees according to a recent estimation [1]. The area of coastal saline soils is expanding and soil salinisation is getting aggravated due to global climate change, seawater intrusion and unreasonable irrigation [2]. The excessive salt causes osmotic stress and ionic stress to decline crop yield so as to constraint the utilisation of coastal saline soils. The coastal saline soils have great potential for utilisation and development to alleviate the problem of land shortage if these soils get effective reclamation and remediation.

Coastal saline soils are generally barren with limited nutrients such as N, P and K. The growth of crop is reduced due to the restriction of nutrients. Therefore, fertilizers are often

CONTACT Jian Lu $\otimes$ jlu@yic.ac.cn E CAS Key Laboratory of Coastal Environmental Processes and Ecological Remediation, Yantai Institute of Coastal Zone Research (YIC), Chinese Academy of Sciences (CAS); Shandong Key Laboratory of Coastal Environmental Processes, YICCAS, Yantai Shandong 264003, People's Republic of China; Center for Ocean MegaScience, Chinese Academy of Sciences, 7 Nanhai Road, Qingdao, 266071, People's Republic of China 
applied excessively in order to ensure grain yield. However, more nutrients get lost thereby, and cause waste of resources due to the lower fertilizer utilisation rate in coastal saline soils. Many studies have demonstrated that increasing the content of soil organic matter not only contributes to nutrient retention, but also improves the soil structure and increases productivity [1,3]. Therefore, the application of organic materials is potential for the amelioration of coastal saline soil.

Among series of organic amendments, leonardite attracts much attention because of its high carbon content, rich functional groups, ubiquitous and cost-effective. Leonardite is an oxidized shallow coal with low combustion value. Therefore, it has no use in the industrial field. However, leonardite is a potential amendment for the coastal saline soil. Studies have demonstrated that the application of leonardite can improve the soil structure, promote the growth of microbial population, and increase crop yield [4]. The abundant humic acids can exchange with soil, subsequently affecting the ions component in the soil [5].

As a cheap and easily-available material, leonardite had the potential to get wide application in the Yellow River Delta. However, the application of leonardite in the study area was scarce. Further study of coastal saline soil using leonardite is needed before wide application. Therefore, commercial leonardite was used to explore the effects on coastal saline soil through the short-term soil incubation. Theoretical basis of leonardite utilisation would be also provided for local saline soil amelioration. It could benefit the sustainable use of other similar organic amendments in the Yellow River Delta area.

\section{Materials and methods}

\section{Soil sampling and leonardite}

The sampling site was located in the Yellow River Delta (N37 $55^{\prime} 14.17^{\prime \prime}$, E118 $48^{\prime} 59.14^{\prime \prime}$ ), China. Over $78 \%$ of annual rainfall concentrates from June to September and the average annual precipitation is only $564 \mathrm{~mm}$ [6]. The top tilled land soil samples $(20 \mathrm{~cm}$ depth) coded as YX1, YX2 and YX3 were collected before winter wheat sowing in October of 2017. The salt content in YX1, YX2 and YX3 was determined as 1.3\%o, 2.6\%o and $9.4 \%$ respectively. Soil samples (YX1, YX2 and YX3) were classified as very slightly saline soil, slightly saline soil, and strongly saline soil $[7,8]$. The soil samples were crushed to pass through the 1-mm sieve after air drying. The soils used in this study were silty clay according to taxonomy of the United States Department of Agriculture (USDA) [9]. The basic properties of the soil were present in Table 1.

Leonardite used in this study was purchased from Shandong Innovation Company. Functional groups carboxyl $(-\mathrm{COOH})$ and phenolic $(-\mathrm{OH})$ was 2.01 and $1.75 \mathrm{~mol} / \mathrm{kg}$, respectively. The $\mathrm{pH}$ of leonardite in water extraction was 3.84 while the electrical conductivity (EC) was $7.84 \mathrm{dS} / \mathrm{m}$ at 1:5 solid-liquid ratio (Table 1 ). The acid leonardite might potentially benefit to neutralize high $\mathrm{pH}$.

\section{Incubation experiment}

Four different amendment dosages (CK of $0 \%$, T1 of $1 \%$, T2 of $3 \%$ and T3 of $5 \%$, ratio of ameliorator: soil) were set by considering the economic cost and results of previous studies in the Yellow River Delta. Leonardite was added to three soils (YX1, YX2, and 
Table 1. Basic properties of coastal saline soil and leonardite.

\begin{tabular}{|c|c|c|c|c|c|c|c|c|c|c|c|c|}
\hline \multicolumn{13}{|c|}{ (a) Basic properties of coastal saline soil } \\
\hline \multirow[b]{2}{*}{ Soil } & \multirow[b]{2}{*}{$\mathrm{pH}$} & \multirow[b]{2}{*}{ EC (dS/m) } & \multirow[b]{2}{*}{$\mathrm{CEC} \mathrm{cmol} / \mathrm{kg}$} & \multirow[b]{2}{*}{ Bulk $\left(\mathrm{g} / \mathrm{cm}^{3}\right)$} & \multirow[b]{2}{*}{ Salinity } & Organic matters & Total N & $\mathrm{PO}_{4}^{3-}$ & Soluble $\mathrm{N}$ & Sand & Silt & Clay \\
\hline & & & & & & \multicolumn{2}{|c|}{$\mathrm{g} / \mathrm{kg}$} & \multicolumn{2}{|c|}{$\mathrm{mg} / \mathrm{kg}$} & \multicolumn{3}{|c|}{ (\%) } \\
\hline YX1 & 7.72 & 0.42 & 15.13 & 1.31 & Very slightly & 9.54 & 0.70 & 0.43 & 3.22 & 15.72 & 39.61 & 44.67 \\
\hline YX3 & 7.43 & 2.89 & 14.09 & & Strongly & 4.26 & 0.94 & 0.74 & 34.34 & 15.08 & 34.95 & 49.96 \\
\hline \multicolumn{13}{|c|}{ (b) Basic properties of leonardite } \\
\hline Amendment & $\mathrm{pH}$ & $\mathrm{EC}(\mathrm{dS} / \mathrm{m})$ & $\mathrm{CEC} \mathrm{cmol} / \mathrm{kg}$ & $-\mathrm{COOH}(\mathrm{mol} / \mathrm{k}$ & & & & phenol- & & Ash & $C(\%)$ & N \\
\hline Leonardite & 3.84 & 7.84 & 163.72 & 2.01 & & & 1.75 & & & 23.70 & 44.21 & 0.91 \\
\hline
\end{tabular}

Note: Electrical conductivity (EC) and $\mathrm{pH}$ were determined at the liquid-soil ratio of 5:1. CEC (cation exchange capacity) was determined using a sodium acetate - flame photometry method; the organic matter in the soil was by potassium dichromate heating method [12]. The machinery composition (sand, silt and clay) was performed by a combination of wet sieving method [15]. $\mathrm{COOH}$ and phenol-OH were determined through titration method provided by the International Humic Substances Society (http://humic-substances.org/). 
$\mathrm{YX} 3)$, and each treatment had three replicates. Urea $\left(\mathrm{CO}\left(\mathrm{NH}_{2}\right)_{2}\right)$ and $\mathrm{KH}_{2} \mathrm{PO}_{4}(\mathrm{~N}$ and $\mathrm{P}$ was equivalent to $0.16 \mathrm{mg} / \mathrm{kg}$ ) were also fully mixed with the coastal saline soils at the beginning of experiment. The prepared soils $(1 \mathrm{~kg})$ were placed in the sealed bag, and sprayed by deionized water (Dl-water) to keep the soil moisture content to $20 \%$. The incubation experiment was conducted in dark under temperature ranging from 23 to $28^{\circ} \mathrm{C}$. Considering the hydrolysis of urea and growth of major local crops, the sampling time was set on the 1st, 8th, 19th, 32nd, 49th and 81st day. Fresh soil with weight of $100 \mathrm{~g}$ in each treatment was collected at each sampling event. $\mathrm{EC}, \mathrm{pH}$, soluble $\mathrm{N}\left(\mathrm{N}-\mathrm{NH}_{4}\right.$ and $\left.\mathrm{N}-\mathrm{NO}_{3}\right)$, soluble $\mathrm{PO}_{4}^{3-}$, urease, and phosphatase were determined. Raman spectrum and X-ray diffraction analysis (XRD) were used to explore the possible functional groups and mineral composition of soils, respectively.

\section{Soil colloid preparation}

Soil colloid extraction experiment was conducted after incubation. In this study, the colloid (particle-size $<2 \mu \mathrm{m}$ ) fraction of soil samples was separated from the soils by sedimentation without chemical pretreatments according to the previous reports $[10,11]$. The settling velocity of a sphere in a medium was proportional to the square of the particle radius but inversely to the viscous coefficient of the medium based on the Stokes' Law. A 3\% (wt/wt) suspension of the air-dried incubated soil was firstly placed in an ultrasonic cleaning tank for a 20-min dispersion to fully resuspend the soil. The upper 10-cm suspension was removed by siphoning after setting for $7 \mathrm{~h}$ at $25 \pm 1^{\circ} \mathrm{C}$. Water removed during the siphoning was replenished, and the dispersion-sedimentation-siphoning process was completed until the upper suspension was clear. Most of particle size below $2 \mu \mathrm{m}$ in the soil was assumed to be removed during this process, and the particle size of the rest was over $2 \mu \mathrm{m}$. The separated soil particles were preserved and frozen-dried for further analysis (C, N and FTIR). The separated soil was saturated in $\mathrm{HCl}(1 \mathrm{~mol} / \mathrm{L})$ for $8 \mathrm{~h}$ to remove the $\mathrm{CaCO}_{3}$ in the soil before analysing $\mathrm{C}$ and $\mathrm{N}$.

\section{Analysis methods and data processing}

Soluble salt content of the soil was determined before experiment based on the residual drying method, and the organic matter in the soil was measured by potassium dichromate heating method [12]. EC was measured by a Rex DDS-11A conductivity meters (Shanghai INESA Scientific Instrument Co., Ltd, China). Contents of soluble $\mathrm{NH}_{4}-\mathrm{N}, \mathrm{NO}_{3}-\mathrm{N}$ and $\mathrm{PO}_{4}^{3-}$ were determined by continuous flowing analyzer (Seal-Branlubbe AA3, German). Total C and $\mathrm{N}$ was determined by high temperature combustion using the elemental analyzer Vario Macro (Elmentar, German). The cation exchange capacity (CEC) of soil samples was measured by $\mathrm{NaOAc}$ exchange [13]. Soil urease and alkaline phosphatase activities (buffer pH of 8) were determined according to Soil Enzyme and Analysis Methods [14]. The soil texture was analysed according to the procedure previously reported [15]. A scanning electron microscope (SEM) (JSM-5610LV, JEOL, Japan) was applied to investigate the surface morphology of soil samples. Fourier transform infrared (FTIR) spectra were obtained by FTIR Nicolet-iS5 (Thermo Fisher Scientific, USA) to analyse the stretching vibration of functional groups of organic matters. The resolution of the scanning spectrum was $4 \mathrm{~cm}^{-1}$ with the sensitivity of $5 \%$, and the measurement range was $400-4000 \mathrm{~cm}^{-1}$. 
Raman spectrum spectra of all incubation samples were obtained by a Microscope Raman Spectrometer (DXR, Thermo Fisher Scientific, USA). The mineral constituents of incubation samples were determined by X-ray diffraction (XRD) spectrometry (Axios, PANalytical, The Netherlands).

Origin 8.1, Excel 2003 and SPSS 19.0 was used for data analysis. One-way ANOVA was performed to determine the difference of the relative parameters, followed by Duncan's multiple comparison test $(P<0.05)$.

\section{Results and discussion}

\section{Effects on EC and pH}

EC, positively related to the concentration of soluble ions, reflects the salinity of coastal saline soil. EC can also become an indicator of biological activity [16]. EC of soil fluctuated during the incubation period (Figure $1(\mathrm{a}-\mathrm{c})$ ). EC of different soils under various treatments changed around 10\% compared with the corresponding initial EC value (Figure 1(a-c)). Moreover, the soil EC value showed an increasing inclination with the addition dosage, which might be ascribed to the soluble ions that induced from leonardite.

The background $\mathrm{pH}$ of $\mathrm{YX} 1 / \mathrm{YX} 2 / \mathrm{YX} 3$ was 7.65/7.56/7.02 (Table 1). The $\mathrm{pH}$ peaks (about 8.2) of all soil samples appeared at the initial incubation period, and then $\mathrm{pH}$ dramatically decreased to a stable state (Figure $1(\mathrm{~d}-\mathrm{f})$ ). Urea $\left(\mathrm{CO}\left(\mathrm{NH}_{2}\right)_{2}\right)$ was added based on the local culture fertilisation in this study. The higher $\mathrm{pH}$ on the $1^{\text {st }}$ day demonstrated the possible $\mathrm{N}$
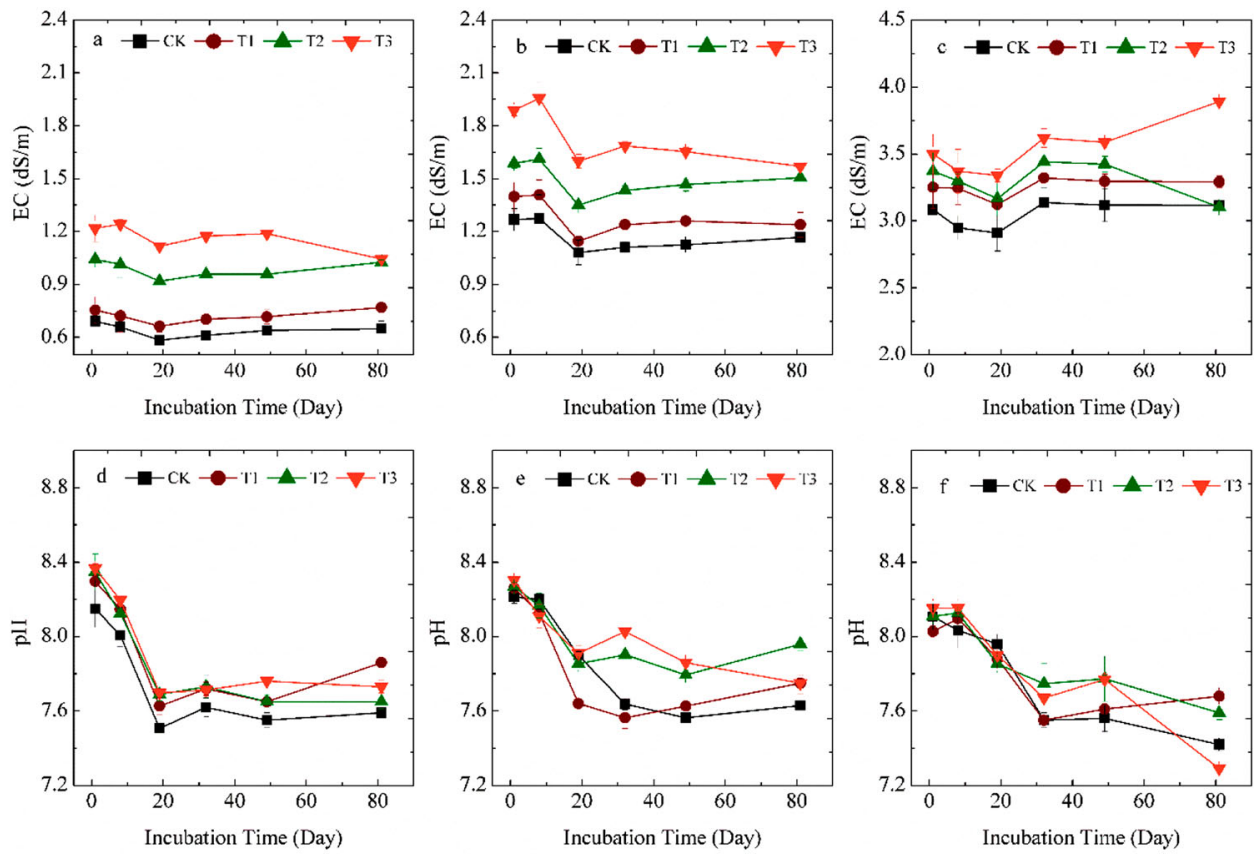

Figure 1. Variation of $E C$ and $\mathrm{pH}$ during incubation time. (a: Variation of $E C$ in $Y X 1$; b: Variation of $E C$ in $\mathrm{YX}$ 2; c: Variation of EC in YX3; d: Variation of $\mathrm{pH}$ in $\mathrm{YX} 1$; e: Variation of $\mathrm{pH}$ in $\mathrm{YX} 2$; $f$ : Variation of $\mathrm{pH}$ in $Y X 3)$. Note: CK was the control; T1 was the treatment of $10 \mathrm{~g} / \mathrm{kg}$ leonardite dosage; T2 was the treatment of $30 \mathrm{~g} / \mathrm{kg}$ leonardite dosage; $\mathrm{T} 3$ was the treatment of $50 \mathrm{~g} / \mathrm{kg}$ leonardite dosage. 
transformation process (Urea $\rightarrow \mathrm{NH}_{4}^{+} \rightarrow \mathrm{NO}_{3}^{-}$). When the $\mathrm{NH}_{3}$ (hydrolysis products of urea) reacted with the soil water $\left(\mathrm{NH}_{3}+\mathrm{H}_{2} \mathrm{O} \leftrightarrow \mathrm{NH}_{3} \cdot \mathrm{H}_{2} \mathrm{O} \leftrightarrow \mathrm{NH}_{4}^{+}+\mathrm{OH}^{-}\right)$, the soil $\mathrm{pH}$ increased correspondingly. As ammonium nitrogen converted into nitrate through nitrification, the $\mathrm{pH}$ of the coastal saline soil decreased gradually, and reached the equilibrium. The variation trend of $\mathrm{pH}$ in soil samples with different salinity was similar through the incubation (Figure 1). However, the salt in soil delayed the decrease of $\mathrm{pH}$. The $\mathrm{pH}$ of YX1 reached the lowest on the 19th day while $\mathrm{pH}$ of YX2 was the lowest on the 32nd day. The $\mathrm{pH}$ of $\mathrm{YX} 3$ showed a decreasing trend during the whole incubation. The $\mathrm{pH}$ of soil treated by leonardite was higher than that of $\mathrm{CK}$, which illustrated the increased capacity of $\mathrm{NH}_{3}-\mathrm{N}$ by leonardite. Therefore, the $\mathrm{N}$ loss declined. The relatively higher $\mathrm{pH}$ demonstrated that urea hydrolysis was more intense and leonardite acted an important role in promoting microbial activity to some extent since soil microorganisms participated in urea degradation [17].

\section{Effect on mineral $\mathrm{N}\left(\mathrm{NH}_{4}-\mathrm{N}, \mathrm{NO}_{3}-\mathrm{N}\right)$ and urease activity}

The peak content of $\mathrm{NH}_{4}-\mathrm{N}$ appeared within a week or so in $\mathrm{YX} 1 / \mathrm{YX} 2 / \mathrm{YX} 3$ (Figure 2). The hydrolysis of urea occurred and $\mathrm{NH}_{4}-\mathrm{N}$ was gradually conversed to $\mathrm{NO}_{3}-\mathrm{N}$ during the incubation process. Consequently, $\mathrm{NO}_{3}-\mathrm{N}$ dominated the soluble $\mathrm{N}$ in the soil at the end of incubation. The content of $\mathrm{NH}_{4}-\mathrm{N}$ in $\mathrm{CK}$ was lower than that treated by leonardite on the whole. Soil salinity might affect the ammonium nitrogen content. Ammonium nitrogen in YX3 (strong salinity) was higher than that of YX1 (very slight salinity) and YX2 (slight salinity). Ammonium nitrogen content in $Y X 3$ reached $99.27 \mathrm{mg} / \mathrm{kg}$, which was 3 and 5 times higher than that of YX2 ( $\max 29.57 \mathrm{mg} / \mathrm{kg})$ and $\mathrm{YX} 1$ ( $\max 18.09 \mathrm{mg} /$ $\mathrm{kg}$ ) respectively. This result might be explained by that microbial activity tended to be reduced at higher salinity to subsequently inhibit the nitrification [3]. The nitrification process of $Y X 1$ and $Y X 2$ reached the balance on the 8th incubation day (Figure 2(d-f)) while nitrification balance in YX3 was delayed due to the inhibition of high salinity. The results indicated that the addition of leonardite accelerated the transformation of nitrate nitrogen, which was consistent with the change of $\mathrm{NH}_{4}-\mathrm{N}$ (Figure 2(a-c)). Moreover, leonardite had limited effect on the $\mathrm{NO}_{3}-\mathrm{N}$ content of coastal saline soils.

The variety of urease activity was divided into two stages including the initial rapid increase of urease activity in coastal saline soils with application of urea and the following gradual decrease period due to the consumption of urea (Figure $2(\mathrm{~g}-\mathrm{i})$ ). The urease activity followed the trend of $Y X 2>Y X 1>Y X 3$ during the whole incubation process. The urease activity in soil YX1 increased with the leonardite dosage and kept the peak from the 8th to 19th day. The highest urease activity of CK/T1/T2/T3 treatment in YX1 was 1.11/ $1.27 / 1.48 / 1.48 \mathrm{mg} /(\mathrm{g} \cdot 24 \mathrm{~h})$. Compared with $\mathrm{CK}$, the urease activity with $\mathrm{T} 1$, $\mathrm{T} 2$, and T3 treatment increased by $9 \%, 24 \%$, and $33 \%$, respectively. The urease activity of CK/T1/T2/T3 treatment in YX2 reached 1.45/1.54/1.62/1.89 mg/(g-24 h). High salt content limited the activity of urease to cause lower urease activity. The urease activity of CK/T1/T2/T3 treatment in $Y X 3$ was 0.68/0.73/1.04/0.97 $\mathrm{mg} /(\mathrm{g} \cdot 24 \mathrm{~h})$, which was lower than that in $\mathrm{YX} 1$ and YX2.

Urea was added to the coastal saline soil as the nitrogen source to simulate the practical farming conditions in this study. Its degradation products $\left(\mathrm{NH}_{4}-\mathrm{N}\right.$ and $\mathrm{NO}_{3}-\mathrm{N}$ ) are regarded as the main inorganic nitrogen sources for plant growth and crop yield [18]. 

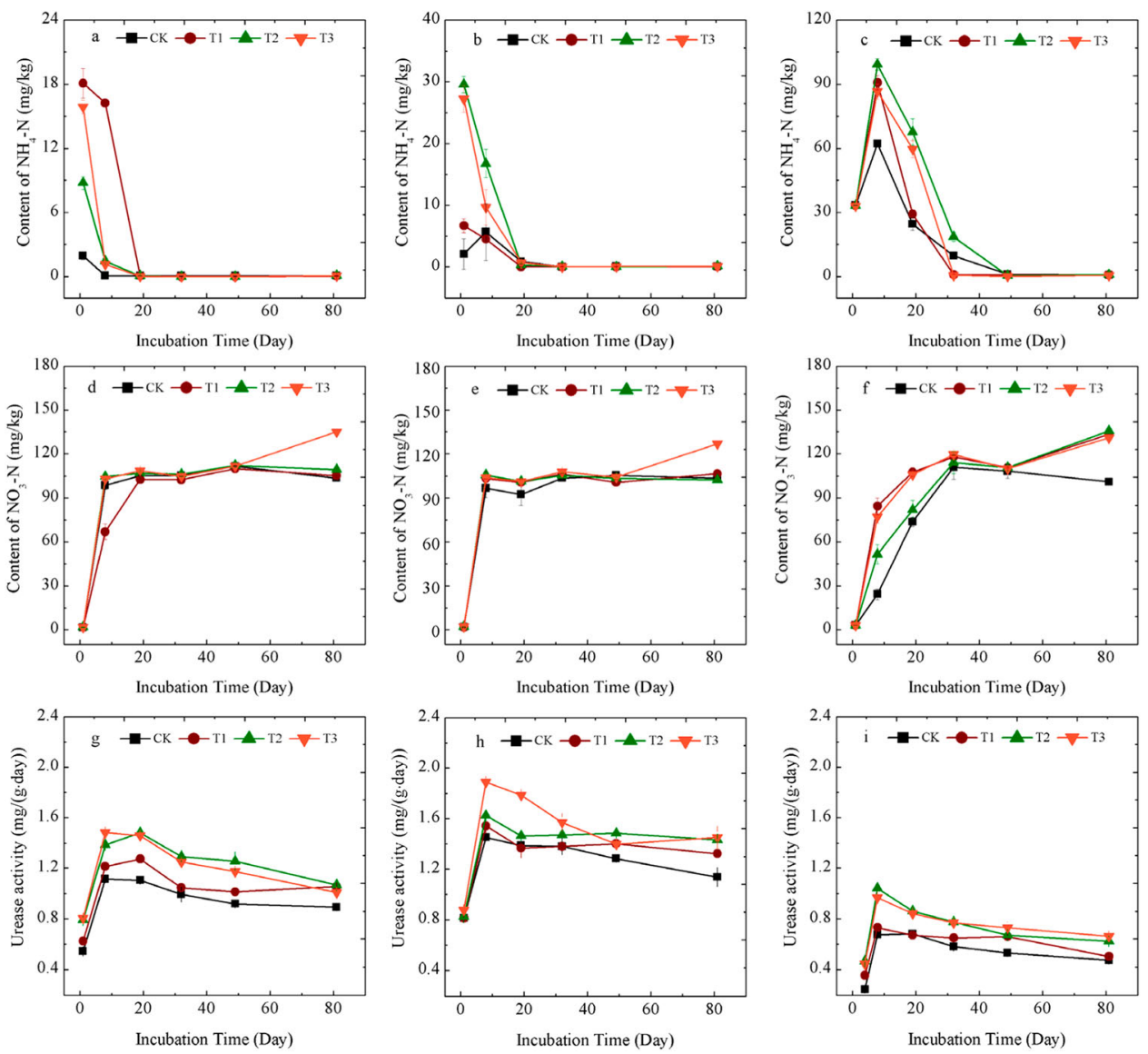

Figure 2. Variation of mineral $\mathrm{N}\left(\mathrm{NH}_{4}-\mathrm{N}\right.$ and $\left.\mathrm{NO}_{3}-\mathrm{N}\right)$ content and urease activity in the soil during the incubation. (a: Variation of $\mathrm{NH}_{4}-\mathrm{N}$ in $\mathrm{YX} 1$; b: Variation of $\mathrm{NH}_{4}-\mathrm{N}$ in $\mathrm{YX2}$; c: Variation of $\mathrm{NH}_{4}-\mathrm{N}$ in $\mathrm{YX} 3$; d: Variation of $\mathrm{NO}_{3}-\mathrm{N}$ in $\mathrm{YX} 1$; e: Variation of $\mathrm{NO}_{3}-\mathrm{N}$ in $\mathrm{YX}$; f: Variation of $\mathrm{NO}_{3}-\mathrm{N}$ in $\mathrm{YX} 3$; g: Variation of urease activity in $\mathrm{YX} 1$; $\mathrm{h}$ : Variation of urease activity in $\mathrm{YX} 2$; i: Variation of urease activity in $\mathrm{YX} 3$ ).

Note: $\mathrm{CK}$ was the control; $\mathrm{T} 1$ was the treatment of $10 \mathrm{~g} / \mathrm{kg}$ leonardite dosage; $\mathrm{T} 2$ was the treatment of $30 \mathrm{~g} / \mathrm{kg}$ leonardite dosage; $\mathrm{T3}$ was the treatment of $50 \mathrm{~g} / \mathrm{kg}$ leonardite dosage.

Results showed that leonardite could provide abundant organic matter for microbes and promote the hydrolysis of urea [17]. The main loss way of urea is ammonia volatilisation in practice [19]. The carboxyl functional groups in leonardite could chemically and physically adsorb $\mathrm{NH}_{4}^{+}$(the formation of ammonium humate) to immobilize ammonium nitrogen in soil and then reduce the volatilisation loss of ammonia [20]. It could also explain why $\mathrm{NH}_{4}^{+}-\mathrm{N}$ in the leonardite group was higher than that of $\mathrm{CK}$ [21]. $\mathrm{NO}_{3}-\mathrm{N}$ is reported to serve as the main nitrogen source for plants [22]. It was the dominant form of ionic $\mathrm{N}$ at the end of the experiment. Results indicated leonardite could not affect the content of $\mathrm{NO}_{3}-\mathrm{N}$ in the soil. Therefore, leonardite was recommended to be applied with urea and other $\mathrm{NH}_{4}-\mathrm{N}$ fertilizer. Urease activity directly reflects the supply capacity of nitrogenous nutrient elements and transformation of mineral fertilizer (urea) in soil [23]. The application of leonardite would have an impact on promoting the soil urease activity which is highly correlated to soil organic matter [24]. 


\section{Effect on $\mathrm{PO}_{4}-\mathrm{P}$ and soil phosphatase activity}

The concentration of phosphorus which is reported to be one of the necessary nutrients in the soil will be essential for plant growth [25]. The concentration of phosphate during the incubation period changed with the similar trend in the soils (Figure $3(\mathrm{a}-\mathrm{c})$ ). $\mathrm{KH}_{2} \mathrm{PO}_{4}$ was introduced as the $\mathrm{P}$ fertilizer to simulate the practical situation before incubation. The highest phosphorous concentration was observed on the 8th incubation day instead of the 1st day. This result was similar to the previous observations [26]. Soluble phosphate would react with irons (e.g. calcium) in the soil, and the fixation took place soon after application. Mineral $P$ was solved and released in soils on the 8 th day due to the vigorous activity of microorganisms. A sharp decrease in soluble phosphorus took place subsequently and the concentration of phosphorus remained at the low level to the final incubation. Soil salinity could affect the concentration of soluble phosphorus due to the general order of YX3 > YX2 > YX1. In addition, soluble phosphate in soil decreased with the addition of leonardite. It was inferred that leonardite not only could promote the retention of phosphate and reduce the risk of leaching, but also would decrease the absorption of phosphorus by crops. Considering this situation, a certain extra amount of phosphate fertilizer should be added combining with leonardite.

The phosphatase activity in all soils was similar (Figure $3(d-f)$ ) during the incubation period (1-81 d), which synchronized with the urease activity (Figure 2). The highest phosphatase activity in $\mathrm{YX} 1$ with CK/T1/T2/T3 was $0.20 / 0.23 / 0.43 / 0.31 \mathrm{mg} /(\mathrm{g} \cdot \mathrm{day})$ while that in YX2 was $0.46 / 0.49 / 0.64 / 0.79 \mathrm{mg} /(\mathrm{g} \cdot$ day) and in $Y X 3$ was $0.65 / 0.53 / 0.60 / 0.68 \mathrm{mg} /(\mathrm{g} \cdot$ day).
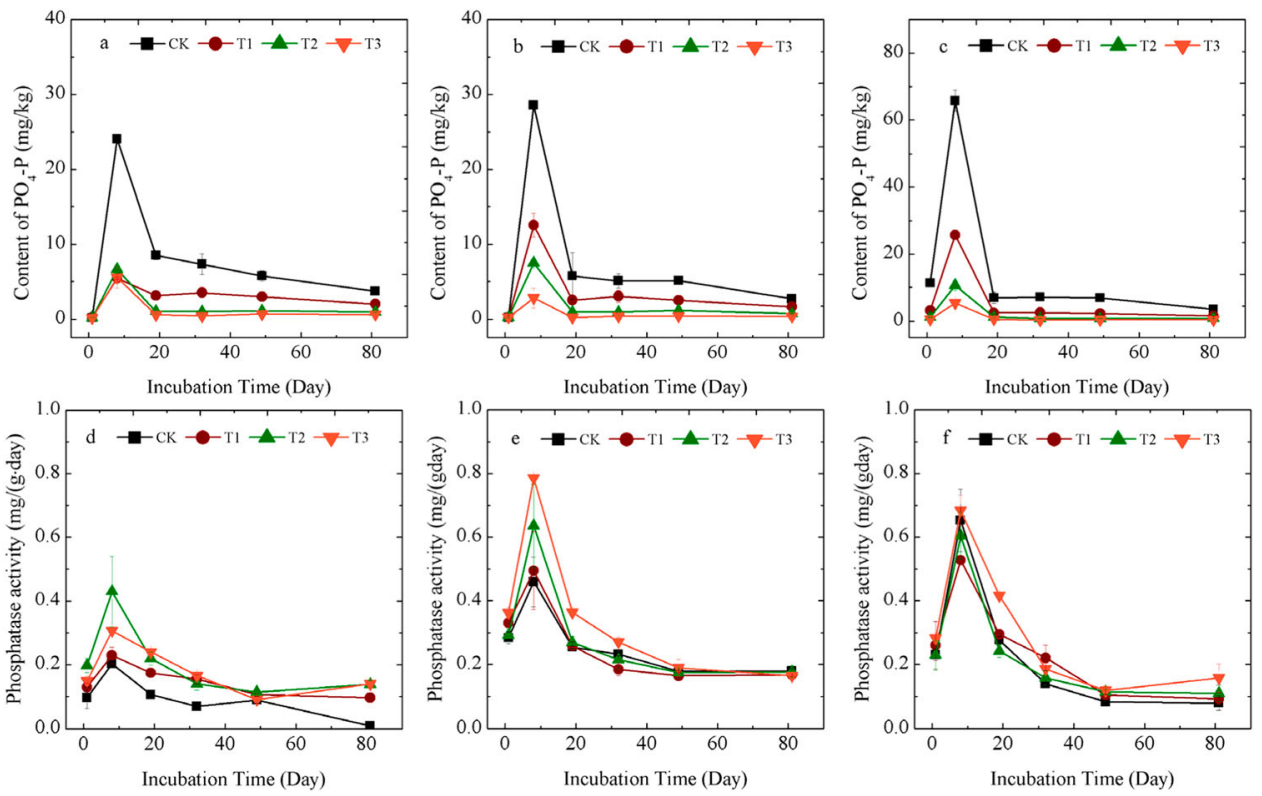

Figure 3. Variation of $\mathrm{PO}_{4}-\mathrm{P}$ content and phosphatase activity in the soil during the incubation. (a: Variation of $\mathrm{PO}_{4}-\mathrm{P}$ in $\mathrm{YX} 1$; $\mathrm{b}$ : Variation of $\mathrm{PO}_{4}-\mathrm{P}$ in $\mathrm{YX} 2$; $\mathrm{c}$ : Variation of $\mathrm{PO}_{4}-\mathrm{P}$ in $\mathrm{YX} 3$; $\mathrm{d}$ : Variation of phosphatase activity in $\mathrm{YX} 1$; e: Variation of phosphatase activity in $\mathrm{YX} 2$; f: Variation of phosphatase activity in $\mathrm{YX} 3$ ). Note: $\mathrm{CK}$ was the control; $\mathrm{T} 1$ was the treatment of $10 \mathrm{~g} / \mathrm{kg}$ leonardite dosage; $\mathrm{T} 2$ was the treatment of $30 \mathrm{~g} / \mathrm{kg}$ leonardite dosage; T3 was the treatment of $50 \mathrm{~g} / \mathrm{kg}$ leonardite dosage. 
Phosphatase activity decreased continually after the 8th day. Moreover, phosphatase activity in soils with leonardite addition treatments was higher than that of CK. Higher leonardite dosage led to higher enzymic activity, indicating that the addition of leonardite provoked the mineralisation of organic phosphorus and solubilisation of the fixed inorganic phosphorous. Soil phosphatase activity was reported to be positively related to soil $\mathrm{C}$ and $\mathrm{N}$ availability [27]. Therefore, the production and release of phosphatase were affected by leonardite.

\section{Effect of leonardite addition on soil texture, morphology and mineral composition}

The soil texture referred to the size and proportion of mineral particles in the soil. It has an important influence on the physio-chemical properties, the aeration, water holding capacity, and fertilizer conservation of soils [28]. The main components of all soil were silt and clay (Table 1), accounting for more than $80 \%$ of soil texture. Previous studies have reported that the leonardite contributed to the formation of soil aggregates to cause changes in soil particle-size fraction [29]. However, the application of leonardite had no obvious effect on the soil texture due to the short-term incubation (Figure 4). The sand percentage in $\mathrm{YX} 1 / \mathrm{YX} 2 / \mathrm{YX} 3$ was $(12.20-20.62 \%) /(7.75-14.88 \%) /(5.44-17.82 \%)$
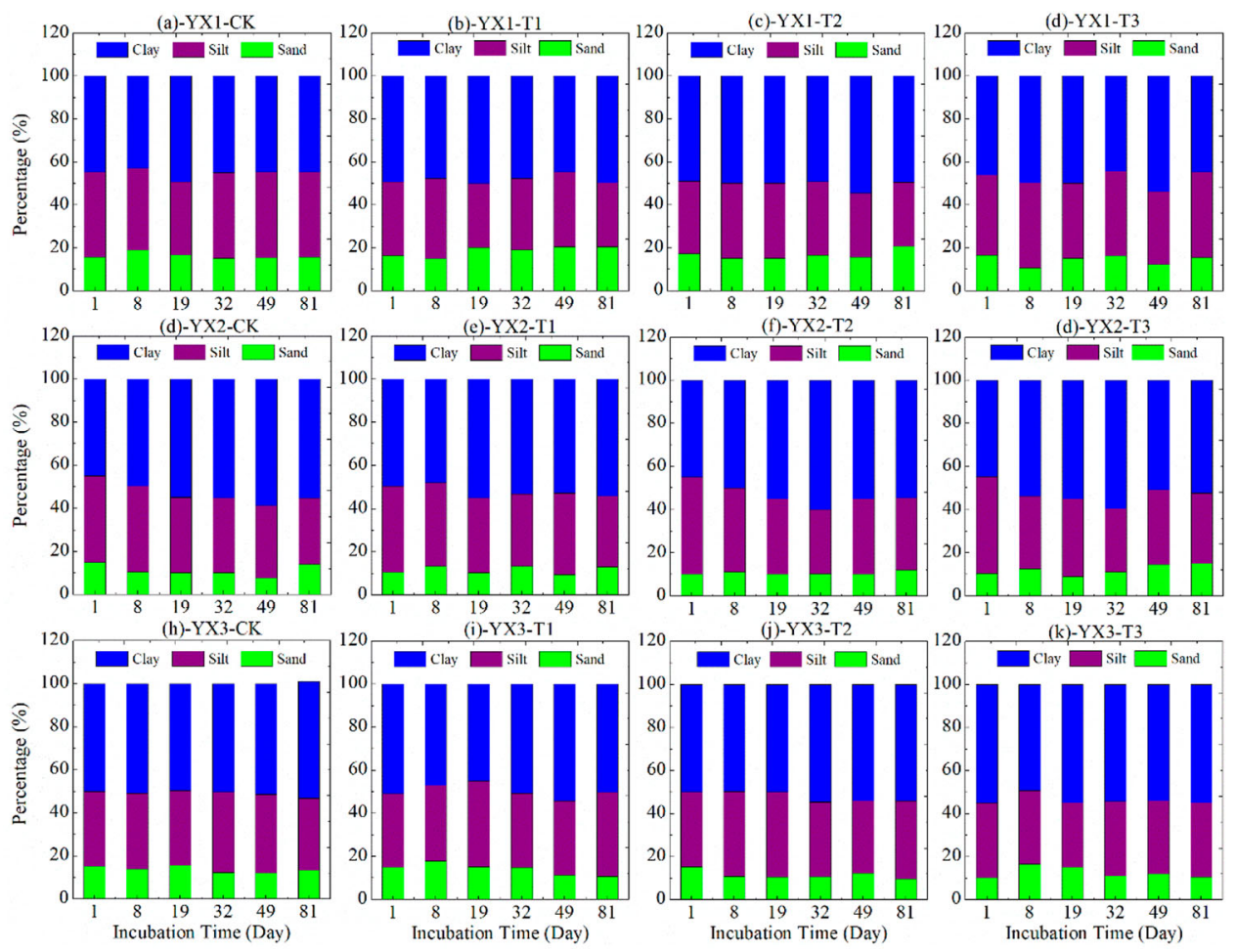

Figure 4. Variation of soil texture $(\mathrm{YX} 1 / \mathrm{YX} 2 / \mathrm{YX} 3)$ during incubation. (CK was the control; $\mathrm{T} 1$ was the treatment of $10 \mathrm{~g} / \mathrm{kg}$ leonardite dosage; $T 2$ was the treatment of $30 \mathrm{~g} / \mathrm{kg}$ leonardite dosage; T3 was the treatment of $50 \mathrm{~g} / \mathrm{kg}$ leonardite dosage. YX1 was very slightly saline soil; YX2 was slightly saline soil; YX3 was strongly saline soil.) 
and silt percentage in $\mathrm{YX1/YX2/YX3}$ was in the range of $(29.76-49.71 \%) /(29.55-44.97 \%) /$ (29.93-39.88\%). Clay in $\mathrm{YX1/YX2/YX3 \text {accountedfor } ( 4 2 . 8 2 - 5 4 . 5 6 \% ) / ( 4 4 . 9 7 - 5 9 . 3 7 \% ) / ~}$ (44.88-54.95\%) during the incubation period.

The micromorphology of coastal saline soils added with leonardite was exhibited by SEM images (Figure 5). The micromorphology of coastal saline soils did not change during the 81-d incubation process with the addition of leonardite. Leonardite was distributed evenly among soil particles.

Raman spectroscopy was used to examine the possible changes of soils during the short incubation (Figure 6) since it was very sensitive to alteration of the carbon structure particularly aliphatic and aromatic fractions of soil components. Fluctuations observed at low shift intervals (below $1000 \mathrm{~cm}^{-1}$ ) reflected soil mineral compositions [30]. The interval $\left(1000-2000 \mathrm{~cm}^{-1}\right.$ ) corresponded precisely to the characteristic of the fulvic and humic molecular fractions of soils [31]. The peaks in this interval were small and dense, indicating that the complex organic might exist in the coastal saline soils. There was a short but wide peak in 2500$3000 \mathrm{~cm}^{-1}$ during the incubation period. The broad band was observed in the range of 0 $3400 \mathrm{~cm}^{-1}$ and the spectra were similar in appearance for all soils. Leonardite failed to affect the carbon structure in soil during the short-term incubation. It implied the effects of leonardite would last for years after application, as only a fraction was initially degraded. Therefore, leonardite had the potential to be a cost-effective material for amelioration of coastal saline soils.

$\mathrm{X}$-ray diffraction analysis was used to identify and to make semiquantitative measurements of the crystalline mineral components of clay fraction. Figure 7 showed the XRD spectra of soil incubated on the 1st and 81st day. A narrow and intense peak was observed at $2 \theta=26.62^{\circ}$, demonstrating the presence of large and ordered crystal particles [32]. The main mineral components of soil were quartz (44-55\%), Albite (12-24\%) and muscovite (18-24\%) which accounted for nearly $90 \%$ of total minerals (Figure 7). The XRD patterns of all soils were similar no matter leonardite added or not. And no significant variation was found between the 1st and 81st day of incubation for all soils, indicating that no precipitates or minerals were formed during the incubation.

\section{Effects of leonardite addition on content of $\mathrm{C}$ and $\mathbf{N}$ distribution among different soils}

Soil colloid is considered to be the smallest and most active part of the soil, which is essential for physio-chemical properties [33]. Soil colloid will play an important role in soil water and fertility retention ability since it has the ability to absorb cations from soil solution [34]. The content of $C$ and $N$ in the separated soil (particle diameter above $2 \mu \mathrm{m}$ was denoted by $S_{A}$; particle diameter below $2 \mu \mathrm{m}$ was denoted by $S_{B}$ ) as well as $C / N$ values were shown in Table 2. The addition of leonardite increased the content of $C, N$ and $C / N$ values. In addition, the content of $C$ and $N$ in $S_{B}$ (the colloid with particle size below $2 \mu \mathrm{m}$ ) was significantly higher than that in the $S_{A}$ (with particle size above $2 \mu \mathrm{m}$ ). Value of $C / N$ showed the opposite trend. The $\mathrm{C} / \mathrm{N}$ value of $\mathrm{YX} 1 / \mathrm{YX} 2 / \mathrm{YX} 3$ in $\mathrm{S}_{\mathrm{A}}$ under T3 treatment (5\% of addition amount) reached 25.15/50.04/53.68 while that in $S_{B}$ was $18.30 / 6.81 / 13.33$. Soil colloid possessed a huge specific surface area, which led to the adsorption of organic matter and nutrients. The addition of leonardite with abundant C (44.21\%) and $\mathrm{N}$ $(0.91 \%)$ significantly increased the content of organic carbon in soil colloid, and would benefit the formation of micro-aggregates in the long term. 


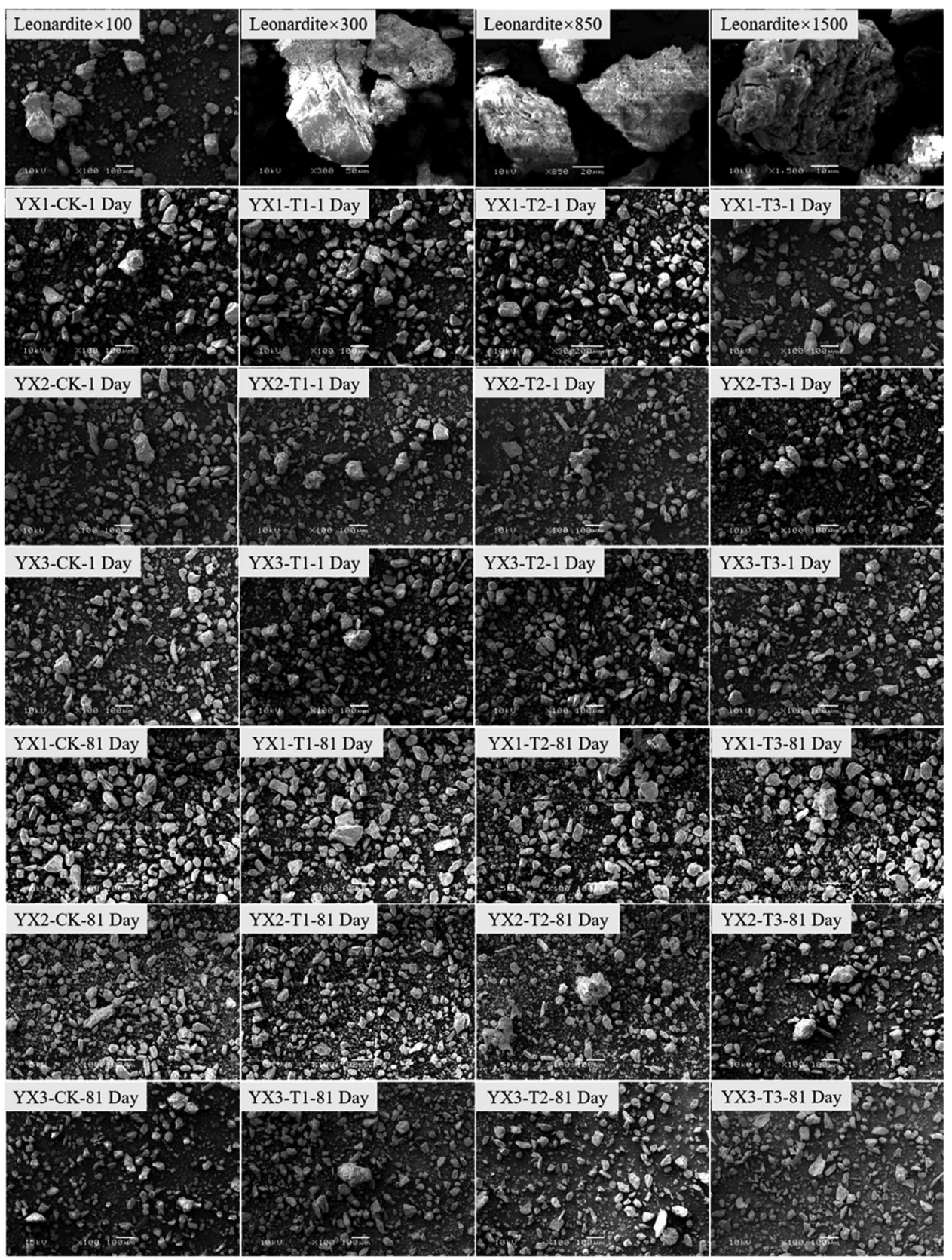

Figure 5. Morphologies of incubated soils in 1st day and 81st day. (CK was the control; T1 was the treatment of $10 \mathrm{~g} / \mathrm{kg}$ leonardite dosage; T2 was the treatment of $30 \mathrm{~g} / \mathrm{kg}$ leonardite dosage; T3 was the treatment of $50 \mathrm{~g} / \mathrm{kg}$ leonardite dosage. YX1 was very slightly saline soil; YX2 was slightly saline soil; YX3 was strongly saline soil).

The FTIR spectral signals of all soils were similar in shape (Figure 8). The intension of signals in $S_{B 1} / S_{B 2} / S_{B 3}\left(S_{B 1}\right.$ was the soil particles below $2 \mu \mathrm{m}$ in $Y X 1$, and the same to $S_{B 2}$ and $\left.\mathrm{S}_{\mathrm{B} 3}\right)$ was higher than that in $\mathrm{S}_{\mathrm{A} 1} / \mathrm{S}_{\mathrm{A} 2} / \mathrm{S}_{\mathrm{A} 3}\left(\mathrm{~S}_{\mathrm{A} 1}\right.$ was the soil particles larger than $2 \mu \mathrm{m}$ 


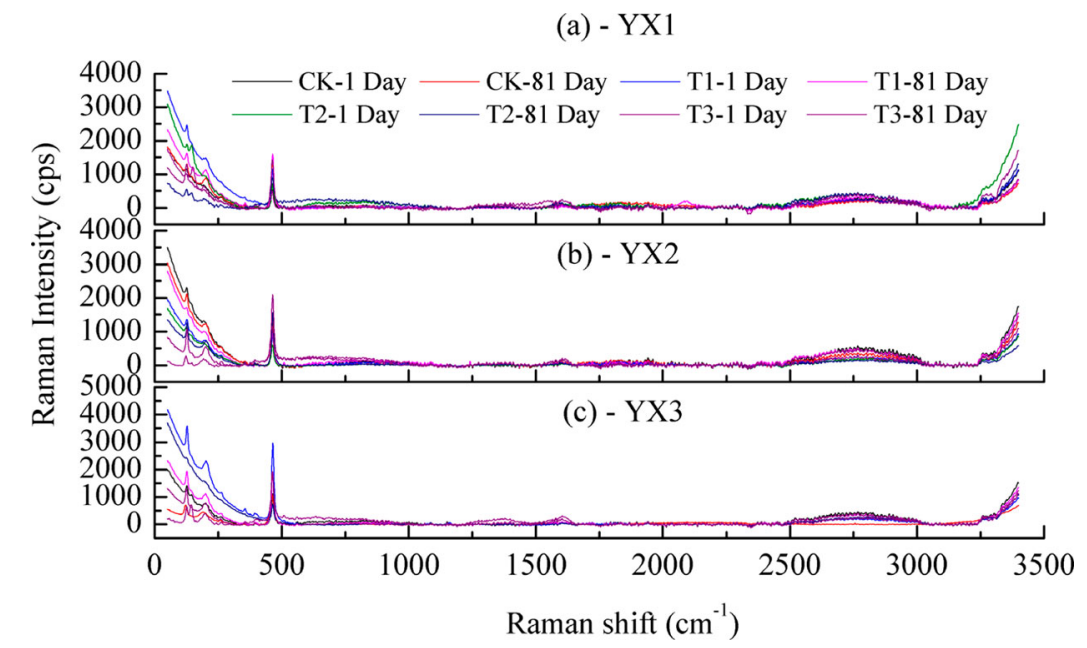

Figure 6. Ramen spectra of incubated soil in 1st day and 81st day. (a: the soil of $\mathrm{YX} 1$ with $\mathrm{CK} / \mathrm{T} 1 / \mathrm{T} 2 / \mathrm{T} 3$; b: the soil of $\mathrm{YX} 2$ with $\mathrm{CK} / \mathrm{T} 1 / \mathrm{T} 2 / \mathrm{T} 3$; $\mathrm{c}$ : the soil of $\mathrm{YX} 3$ with $\mathrm{CK} / \mathrm{T} 1 / \mathrm{T} 2 / \mathrm{T} 3)$.

Note: CK was the control; T1 was the treatment of $10 \mathrm{~g} / \mathrm{kg}$ leonardite dosage; T2 was the treatment of $30 \mathrm{~g} / \mathrm{kg}$ leonardite dosage; T3 was the treatment of $50 \mathrm{~g} / \mathrm{kg}$ leonardite dosage. YX1 was very slightly saline soil; YX2 was slightly saline soil; YX3 was strongly saline soil.

Table $2 \mathrm{C}, \mathrm{N}$ content and $\mathrm{C} / \mathrm{N}$ value in particle-size separated soil

\begin{tabular}{|c|c|c|c|c|c|c|c|}
\hline \multirow[b]{2}{*}{ Soil } & \multirow[b]{2}{*}{ Treatment } & \multicolumn{2}{|c|}{$\mathrm{C} \%$} & \multicolumn{2}{|c|}{$\mathrm{N} \%$} & \multicolumn{2}{|c|}{$\mathrm{C} / \mathrm{N}$} \\
\hline & & $\begin{array}{l}\text { Patical size } \\
<2 \mu \mathrm{m}\end{array}$ & $\begin{array}{l}\text { Patical size } \\
>2 \mu \mathrm{m}\end{array}$ & $\begin{array}{l}\text { Patical size } \\
\quad<2 \mu \mathrm{m}\end{array}$ & $\begin{array}{l}\text { Patical size } \\
>2 \mu \mathrm{m}\end{array}$ & $\begin{array}{l}\text { Patical size } \\
\quad<2 \mu \mathrm{m}\end{array}$ & $\begin{array}{l}\text { Patical size } \\
>2 \mu \mathrm{m}\end{array}$ \\
\hline \multirow[t]{4}{*}{ YX1 } & CK & $1.51 \pm 0.02 \mathrm{a}$ & $0.93 \pm 0.10 a$ & $0.24 \pm 0.00 a$ & $0.07 \pm 0.00 a$ & $6.28 \pm 0.10 a$ & $14.32 \pm 1.49 a$ \\
\hline & $\mathrm{T} 1$ & $1.79 \pm 0.02 b$ & $1.23 \pm 0.06 b$ & $0.22 \pm 0.00 a$ & $0.08 \pm 0.00 \mathrm{a}$ & $8.13 \pm 0.14 b$ & $15.47 \pm 0.70 a$ \\
\hline & $\mathrm{T} 2$ & $2.77 \pm 0.04 c$ & $2.37 \pm 0.02 c$ & $0.20 \pm 0.00 \mathrm{~b}$ & $0.11 \pm 0.00 b$ & $13.85 \pm 0.21 c$ & $21.54 \pm 0.15 b$ \\
\hline & T3 & $4.21 \pm 0.18 d$ & $3.27 \pm 0.08 d$ & $0.23 \pm 0.01 a$ & $0.13 \pm 0.00 b$ & $18.30 \pm 0.05 d$ & $25.15 \pm 1.21 c$ \\
\hline \multirow[t]{4}{*}{$Y X 2$} & CK & $1.75 \pm 0.33 a$ & $0.54 \pm 0.01 a$ & $0.44 \pm 0.01 a$ & $0.04 \pm 0.00 \mathrm{a}$ & $4.71 \pm 0.69 a b$ & $14.30 \pm 0.72 a$ \\
\hline & $\mathrm{T} 1$ & $2.02 \pm 0.01 a$ & $1.04 \pm 0.05 b$ & $0.45 \pm 0.01 a$ & $0.06 \pm 0.01 \mathrm{ab}$ & $4.50 \pm 0.07 a$ & $17.85 \pm 4.08 b$ \\
\hline & $\mathrm{T} 2$ & $2.87 \pm 0.02 b$ & $1.76 \pm 0.04 c$ & $0.50 \pm 0.01 b$ & $0.06 \pm 0.01 \mathrm{ab}$ & $5.70 \pm 0.00 b$ & $30.53 \pm 2.53 b$ \\
\hline & T3 & $3.55 \pm 0.03 c$ & $2.76 \pm 0.03 d$ & $0.52 \pm 0.00 c$ & $0.05 \pm 0.01 b$ & $6.81 \pm 0.09 b$ & $50.04 \pm 5.11 c$ \\
\hline \multirow[t]{4}{*}{ YX3 } & CK & $1.98 \pm 0.09 a$ & $0.77 \pm 0.02 a$ & $0.31 \pm 0.01 a$ & $0.05 \pm 0.01 a$ & $6.39 \pm 0.12 a$ & $16.28 \pm 1.03 a$ \\
\hline & T1 & $2.45 \pm 0.03 b$ & $0.57 \pm 0.05 b$ & $0.30 \pm 0.01 \mathrm{a}$ & $0.04 \pm 0.00 a$ & $8.18 \pm 0.06 b$ & $16.37 \pm 3.51 a$ \\
\hline & $\mathrm{T} 2$ & $3.84 \pm 0.03 c$ & $1.56 \pm 0.13 c$ & $0.36 \pm 0.00 b$ & $0.05 \pm 0.00 a$ & $10.69 \pm 0.33 c$ & $28.72 \pm 4.25 b$ \\
\hline & $\mathrm{T} 3$ & $4.90 \pm 0.12 \mathrm{~d}$ & $1.84 \pm 0.05 d$ & $0.37 \pm 0.01 b$ & $0.03 \pm 0.01 b$ & $13.33 \pm 0.24 d$ & $53.68 \pm 1.56 c$ \\
\hline
\end{tabular}

Note: CK was the control; T1 presented the treatment of $10 \mathrm{~g} / \mathrm{kg}$ leonardite dosage; T2 presented the treatment of $30 \mathrm{~g} / \mathrm{kg}$ leonardite dosage; T3 presented the treatment of $50 \mathrm{~g} / \mathrm{kg}$ leonardite dosage.

in $Y X 1$, and the same to $S_{A 2}$ and $S_{A 3}$ ). Wavenumbers in the range of $500-1200 \mathrm{~cm}^{-1}$ generally indicate the specific absorptions of soil minerals such as clay, quartz or iron oxides [35]. Obvious peaks were detected at $996.20 \mathrm{~cm}^{-1}$ in YX1, YX2, and YX3 (Figure 8), indicating many minerals existed in the particles. $C=O$ vibrational peaks at $1620 \mathrm{~cm}^{-1}$ were mainly from functional groups amides, carboxylic acids and aromatic [35,36]. The broad band from 3000 to $3500 \mathrm{~cm}^{-1}$ was probably the result of the $\mathrm{O}-\mathrm{H}$ and $\mathrm{N}-\mathrm{H}$ stretching vibrations of water and organic materials such as alcohols, phenols and amides. The absorbance at 1620 and $3365 \mathrm{~cm}^{-1}$ in $\mathrm{S}_{\mathrm{A}}$ was obviously weaker than that of $\mathrm{S}_{\mathrm{B}}$, which indicated that the soil with small particle size contains more humic acids from leonardite. It is important for the formation of soil aggregates and the improvement of soil structure. 
(a)-YX1

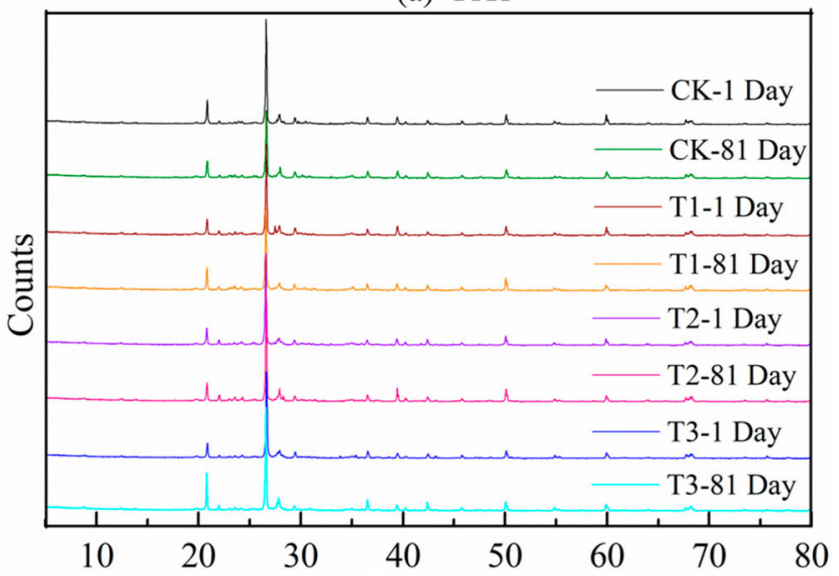

(b)-YX2

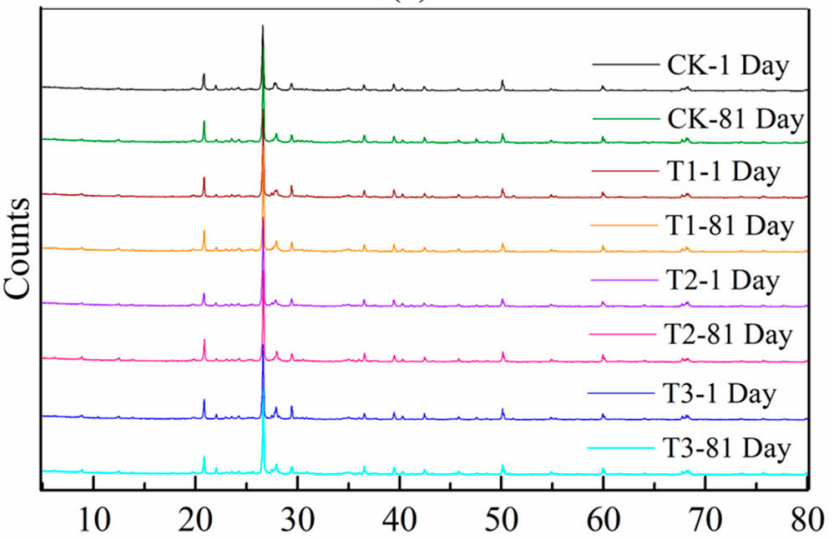

(c)-YX3

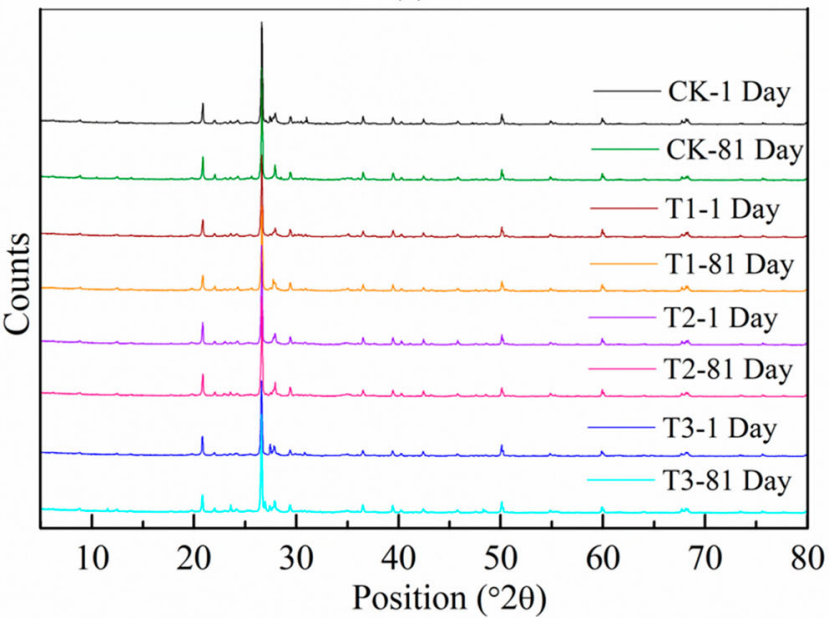

31

Figure 7. X-ray diffraction of the incubated soil. Note: CK was the control; T1 was the treatment of $10 \mathrm{~g} /$ $\mathrm{kg}$ leonardite dosage; T2 was the treatment of $30 \mathrm{~g} / \mathrm{kg}$ leonardite dosage; T3 was the treatment of $50 \mathrm{~g} / \mathrm{kg}$ leonardite dosage. YX1 was very slightly saline soil; YX2 was slightly saline soil; YX3 was strongly saline soil. 


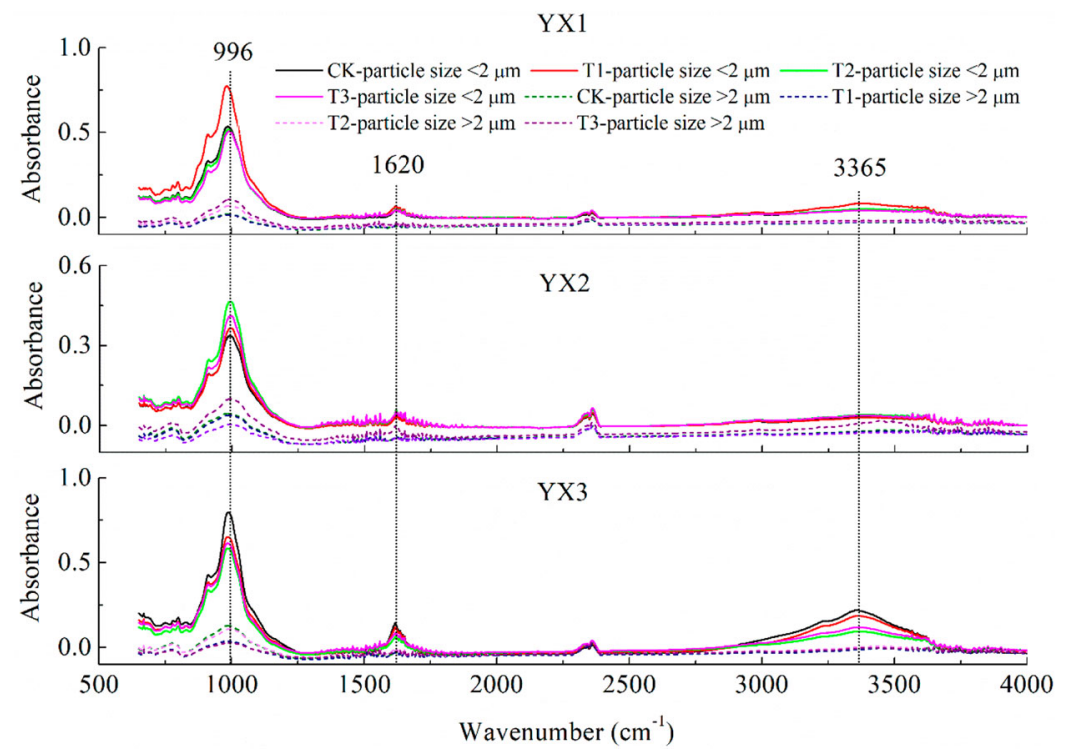

Figure 8. FTIR of particle separated soil.

Note: $\mathrm{CK}$ was the control; $\mathrm{T} 1$ was the treatment of $10 \mathrm{~g} / \mathrm{kg}$ leonardite dosage; $\mathrm{T2}$ was the treatment of $30 \mathrm{~g} / \mathrm{kg}$ leonardite dosage; T3 was the treatment of $50 \mathrm{~g} / \mathrm{kg}$ leonardite dosage. YX1 was very slightly saline soil; YX2 was slightly saline soil; YX3 was strongly saline soil.

\section{Conclusions}

The addition of leonardite increased the content of organic matter. The activity of urease and phosphatase subsequently increased with the accelerated hydrolysis of urea and the decreased content of soluble phosphate in the soil. Leonardite increased the $\mathrm{C}$ and $\mathrm{N}$ content as well as $\mathrm{C} / \mathrm{N}$ in the soil colloid of the incubated soil. However, the leonardite addition had little effect on the soil texture and mineral composition during the shortterm incubation. Overall, the application of leonardite would introduce organic matter to promote the activity of soil microbe and relative enzyme, and the soil ecosystem would thereby get improved.

\section{Acknowledgements}

This work was supported by National Natural Science Foundation of China (41671319), the Chinese National Key Research and Development Program (2016YFD0200303), Taishan Scholar Program of Shandong Province (No. tsqn201812116), One Hundred Talents Program of Chinese Academy of Sciences (Y629041021), Science and Technology Service Network Initiative of the Chinese Academy of Sciences (KFJ-STS-QYZX-114), Youth Innovation Team Project for Talent Introduction and Cultivation in Universities of Shandong Province, and Two-Hundred Talents Plan of Yantai (Y739011021). The authors would like to thank the reviewers for their valuable suggestions and comments on the manuscript.

\section{Disclosure statement}

No potential conflict of interest was reported by the author(s). 


\section{Funding}

This work was supported by the National Natural Science Foundation of China [grant number 41671319]; the Chinese National Key Research and Development Program [grant number 2016YFD0200303]; Science and Technology Service Network Initiative of the Chinese Academy of Sciences [grant number KFJ-STS-QYZX-114]; One Hundred Talents Program of Chinese Academy of Sciences [grant number Y629041021]; Youth Innovation Team Project for Talent Introduction and Cultivation in Universities of Shandong Province; Taishan Scholar Program of Shandong Province [grant number No. tsqn201812116]; Two-Hundred Talents Plan of Yantai [grant number Y739011021].

\section{Notes on contributors}

Jie Wang is a Ph.D candidate with major of environmental engineering.

Jun $W u$ is a professor in the field of environmental engineering.

Jian $L u$ is a professor in the field of environmental engineering.

Guodong Yuan is a professor in the field of saline soil remediation.

\section{References}

[1] Akhtar SS, Andersen MN, Liu F. Biochar mitigates salinity stress in potato. J Agron Crop Sci. 2015;201:368-378.

[2] Wong VN, Greene RSB, Dalal RC, et al. Soil carbon dynamics in saline and sodic soils: a review. Soil Use Manage. 2010;26:2-11.

[3] Zhou M, Butterbach-Bahl K, Vereecken $\mathrm{H}$, et al. A meta-analysis of soil salinization effects on nitrogen pools, cycles and fluxes in coastal ecosystems. Glob Change Biol. 2017;23:1338-1352.

[4] Dobrzanski A, Anyszka Z. Response of carrots to application of natural extracts from seaweed (sargassum sp.) - algaminoplant and from leonardite - humiplant. J Res Appl Agricult Eng. 2008;53:53-58.

[5] Barone V, Bertoldo G, Magro F, et al. Molecular and Morphological changes induced by leonardite-based biostimulant in Beta vulgaris L. Plants. 2019;8:181.

[6] Mao W, Kang S, Wan Y, et al. Yellow River sediment as a soil amendment for amelioration of saline land in the Yellow River delta. Land Degrad Dev. 2016;27:1595-1602.

[7] Wang ZQ. Salt affected soils of China. Beijing: China Science Press; 1997; Chinese.

[8] Shahid SA, Zaman M, Heng L. Introduction to soil salinity, sodicity and diagnostics techniques. In: Zaman M, Shahid SA, Heng L, editors. Guideline for salinity assessment, mitigation and adaptation using nuclear and related techniques. Springer International Publishing; 2018. p. 5-13.

[9] Shirazi MA, Boersma L. A unifying quantitative analysis of soil texture. Soil Sci Soc Am J. 1984;48:142-147.

[10] Xiong Y. Soil. Colloids: Il. The investigation method on soil colloids. Beijing: China Science Press; 1983; Chinese.

[11] Hu J, Shen Y, Wang X. The effect of ionic strength and $\mathrm{pH}$ conditions on the release, deposition and dispersibility behaviors of natural soil colloid. Ecology and Environment. 2009;18:629-637.

[12] Bao SD. Soil Agro-chemistrical analysis. 3rd ed. Beijing: China Agriculture Press; 2000; p. 187440. Chinese.

[13] Page AL, Miller RH, Keeney DR. Methods of soil analysis. Part 2. Chemical and Microbiological properties; American Society of Agronomy. Madison (WI): Soil Science Society of America; 1982; pp. 159-165.

[14] Guan S. Soil enzyme and analysis Methods. Beijing: China Agricultural Press; 1986; Chinese.

[15] Klute A. Methods of soil analysis. Madison (WI): Soil Science Society of America; 1986; Part 1, Physical and Mineralogical Methods; p. 383-412. 
[16] Corwin DL, Yemoto K. Salinity: electrical conductivity and total dissolved solids. Methods of soil analysis. msaonline2017; 2017.

[17] Rinaldi LF, Garcia PL, Sermarini RA, et al. ${ }^{15} \mathrm{~N}$-urea efficiency in maize as influenced by humic substances and urease Inhibitors treatments. Commun Soil Sci Plant Anal. 2019;50:198-208.

[18] Xing S, Wang J, Zhou Y, et al. Effects of $\mathrm{NH}_{4}^{+}-\mathrm{N}^{-} \mathrm{NO}_{3}^{-}-\mathrm{N}$ ratios on photosynthetic characteristics, dry matter yield and nitrate concentration of spinach. Exp Agric. 2015;51:151-160.

[19] Demirer T. Effect of leonardite application on leaf nutrient content and fruit chemical parameters of cherry (Prunus avium L.). J Plant Nutr. 2019;42(19):2532-2538.

[20] Olaetxea M, De Hita D, Garcia CA, et al. Hypothetical framework integrating the main mechanisms involved in the promoting action of rhizospheric humic substances on plant root- and shoot- growth. Appl Soil Ecol. 2018;123:521-537.

[21] Abiala MA, Abdelrahman M, Burritt DJ, et al. Salt stress tolerance mechanisms and potential applications of legumes for sustainable reclamation of salt-degraded soils. Land Degrad Dev. 2018;29:3812-3822.

[22] Xu L, Cheng S, Fang $\mathrm{H}$, et al. Soil inorganic nitrogen composition and plant functional type determine forage crops nitrogen uptake preference in the temperate cultivated grassland, Inner Mongolia. Soil Sci Plant Nutr. 2019;65:1-10.

[23] Baddam R, Reddy GB, Raczkowski C, et al. Activity of soil enzymes in constructed wetlands treated with swine wastewater. Ecol Eng 2016;91:24-30.

[24] Xie X, Pu L, Wang Q, et al. Response of soil physicochemical properties and enzyme activities to long-term reclamation of coastal saline soil, Eastern China. Sci Total Environ. 2017;607:14191427.

[25] Kudoyarova GR, Vysotskaya LB, Arkhipova TN, et al. Effect of auxin producing and phosphate solubilizing bacteria on mobility of soil phosphorus, growth rate, and $\mathrm{P}$ acquisition by wheat plants. Acta Physiol Plant. 2017;39:253.

[26] Tao G, Tian S, Cai M, et al. Phosphate-solubilizing and -mineralizing abilities of bacteria isolated from soils. Pedosphere. 2008;18:515-523.

[27] Hou E, Chen C, Wen D, et al. Phosphatase activity in relation to key litter and soil properties in mature subtropical forests in China. Sci Total Environ. 2015;515:83-91.

[28] $\mathrm{Wu}$ J, Li Z, Gao Z, et al. Degraded land detection by soil particle composition derived from multispectral remote sensing data in the Otindag Sandy Lands of China. Geoderma. 2015;241:97-106.

[29] Volikov AB, Kholodov VA, Kulikova NA, et al. Silanized humic substances act as hydrophobic modifiers of soil separates inducing formation of water-stable aggregates in soils. Catena. 2016;137:229-236.

[30] Luna AS, Lima IC, Rocha WF, et al. Classification of soil samples based on Raman spectroscopy and X-ray fluorescence spectrometry combined with chemometric methods and variable selection. Anal Methods. 2014;6:8930-8939.

[31] Edwards H, Munshi T, Scowen I, et al. Development of oxidative sample preparation for the analysis of forensic soil samples with near-IR Raman spectroscopy. J Raman Spectrosc. 2012;43:323-325.

[32] Zhao B, Nan X, Xu H, et al. Sulfate sorption on rape (Brassica campestris L.) straw biochar, loess soil and a biochar-soil mixture. J Environ Manage. 2017;201:309-314.

[33] Yan J, Lazouskaya V, Jin Y. Soil colloid release affected by dissolved organic matter and redox conditions. Vadose Zone J. 2016;15:1-10.

[34] Huang LM, Zhang XH, Shao MA, et al. Pedogenesis significantly decreases the stability of waterdispersible soil colloids in a humid tropical region. Geoderma. 2016;274:45-53.

[35] Xing Z, Du C, Tian K, et al. Application of FTIR-PAS and Raman spectroscopies for the determination of organic matter in farmland soils. Talanta. 2016;158:262-269.

[36] Wang $Y$, Zhang X, Zhang X, et al. Characterization of spectral responses of dissolved organic matter (DOM) for atrazine binding during the sorption process onto black soil. Chemosphere. 2017;180:531-539. 